\title{
Public Health Promotion: Autonomy of the Emergency Nurse Practitioner
}

\author{
Cheryl Ann Alexander ${ }^{1}$, Lidong Wang ${ }^{2}$ \\ ${ }^{1}$ Department of Nursing, University of Phoenix, USA \\ ${ }^{2}$ Department of Engineering Technology, Mississippi Valley State University, USA
}

\begin{abstract}
The purpose of this paper is to examine several key issues in health care reform. From the Patient Protection and Affordable Care Act of 2010 to the cholera epidemic in Haiti, global health care reform is necessary to promote health and wellness among all nations. There is an international shortage of nurses and nursing faculty. Among the providers, it is also necessary to examine autonomy of the most up and coming nurse provider: the emergency nurse practitioner.
\end{abstract}

Keyword:

Autonomy

Evaluation and intervention

Infectious diseases

Nursing shortage

Public health promotion

Copyright (C) 2015 Institute of Advanced Engineering and Science. All rights reserved.

\section{Corresponding Author:}

Lidong Wang,

Department of Engineering Technology,

Mississippi Valley State University,

14000 Hwy, 82 West, IttaBena, Mississippi 38941, USA.

Email: lwang22@students.tntech.edu

\section{INTRODUCTION}

Although the United States spends more on health care than all the industrialized nations, 65 million residents still remain uninsured [1]. The Patient Protection and Affordable Care Act (ACA) was enacted in 2010 in an attempt to solve the problem of the millions without insurance. Thousands of pages long, many legislators had not read the whole bill nor did they understand it. It passed with Democratic support only and not one Republican vote supported its enactment. The bill's major provisions will take effect in 2014, 2018, and 2020. Dubbed "Obamacare” by skeptical, resistant Republicans, the bill has been a source of controversy since its inception. Although there was dissatisfaction with the country's health care system, the ACA was relatively unpopular and the subject of many debates. Recently the ACA has been under fire as the subject of lawsuits claiming the bill violates the public's civil rights. Lawmakers continue to debate the ethics behind the bill and organizations such as the American Medical Association (AMA) and the American Association of Retired Persons (AARP) continue to argue against the economics of the health care reform bill [2].

The Institute of Medicine (IOM) estimates between 44,000 and 99,000 people die in hospitals every year from medical errors. Medical errors are the eighth leading cause of death in the US. The US ranks last out of 16 industrialized nations in regards to deaths as a result of medical errors. Statistics from the IOM average one in five patients are readmitted to the hospital within 30 days of discharge. The average per capita expense for a US patient is $\$ 8,508$, second only to Norway [1].

Crucial to the ACA is every American's right to health insurance. Federal funding on the bill is expected to reach $\$ 938$ billion over a decade, according to a non-partisan Congressional Budget Officer [3]. States may be expected to fund their own private insurance exchanges, but most states are waiting to see what happens to the Obama administration's bill after a Supreme Court decision or the November election 
results may repeal part or the entire bill [4]. An addition 34 million people are expected to be on the rolls of the insured lists by 2021, increasing the percentage of non-elderly Americans with insurance from 83\% to 95\% if the ACA survives its current legal battles. One strong point in favor of the reform is the opportunity for health care prevention. The ACA has an opportunity to reorient the American health care system to a health prevention system rather than a health care system. Currently $95 \%$ of medical dollars is spent on medical care and only $1-2 \%$ is spent on prevention [5].

The ACA has five cost control tools: the Cadillac tax, exchanges, comparative effectiveness research, and the independent payment advisory board. These tools help control spending and budget for controlling health care spending in the coming decade. Medicare and Medicaid spending is out of control. The ACA is using some tools to cut costs and develop a more comparative cost per service health care system. The health insurance exchanges will ensure that people will get good deals on insurance as the competition will drive prices lower; or so that is the projected scenario [6].

Probably the most notable aspect of the ACA is the individual mandate of the bill. This mandate is the subject of lawsuits and controversy. The individual mandate requires that some 50 million uninsured Americans buy insurance by 2014. This "lightening rod" of the bill contains the very heart of the ACA. Preventive services can be served under the individual mandate. The ACA changes the way Americans perceive health by promoting public health as they take on these insurance policies and receive health care for the first time in some cases [7].

The ACA is changing the face of health care in America, good or bad. Americans spend millions of dollars on health care every year. The government is intervening by mandating public health insurance for all, in essence by promoting a public health policy. Organizations such as the AMA and AARP will continue to fight on as the arguments over the ACA continue. Politics will drive the bill until the Supreme Court has heard the case on the grounds for the individual mandate. While many have never read the bill in its entirety, health care reform is necessary; whether or not it is in the form of the ACA remains to be seen.

Within this culture of health care reform, it is important that several factors are examined such as new graduate nurses, the autonomy of the nurse practitioner which will become a driving force behind providers in rural and urban areas in the coming years, and several global factors that drive health care. In this paper, health care reform, economics and the new graduate, the shortage of nurses, autonomy of the emergency nurse practitioner, acute global issues will be examined.

\section{ECONOMICSAND THE NEW GRADUATE}

Climate change will have a strong impact on the future of nursing. Most nursing students leave nursing school with the hope of finding a job right away. After all, there is a national nursing shortage. However, the facts may fall in a far different economic direction for the new graduate. While national statistics indicate the current nursing shortage will grow to over one million nurses by the year 2020, not all regions may be affected by the shortage. Current graduates are finding it more difficult to find jobs in some regions. Reasons for the difficulties in finding a job include: nurses returning to the workforce due to the economic recession, more nurses increasing hours, and increased competition for available slots [8]. Nursing schools are ill-prepared to handle the current economic state of the job market. Contributing factors include: difficulties in finding clinical sites, decreased numbers of faculty, and rising numbers of nursing school applicants [9]. In this paper, the current economic state of nursing education and the job market will be examined with regard to the 2008 Regression.

Despite the current regression, jobs in the health care field have remained steady. With the number of Americans growing older and 38\% of hospitalized patients comprised of older Americans, nurses are still in high demand [10]. Adams reports on a new initiative by Michigan's Oakland State University to diversify its nursing education program to include more clinical sites and better training for its new graduates. A lack of faculty and difficulty in finding clinical sites make it difficult to prepare students adequately to meet the needs of employers looking to fill vacancies [9]. At Oakland State University, partnerships with health care organizations are helping to fill the gap between finding clinical sites and adjunct faculty [10].

With the dwindling supply of experienced nurses, more and more hospitals will have to fill vacancies with inexperienced nurses. Within the next decade, a 50\% turnover of nurses is expected. To combat these statistics, nurse residency programs have been implemented by some states and nursing schools to prepare nursing students to meet the challenges of the workforce [11]. This increases the competence level of new graduates.

The expectations of new graduate education have increased by hospitals. Nursing schools are increasingly investing in technology such as simulators. Better training will help new graduates find jobs faster than traditional programs. In addition, cooperation between organizations and nursing school will strengthen the new graduate job market [12].

IJPHS Vol. 4, No. 1, March 2015 : 27 - 36 
Terry and Whitman [9] report that nursing schools will need to rise to meet the economic challenges facing nursing students. Creative methods in finding jobs and recruitment efforts will only enhance the new graduate experience. Nurse educators must strive to prepare students to meet real world challenges so that finding a job is not only easier, but offers a more secure future.

Climate change has been foretold as the biggest global event in this century. Topics such as how the global climate affects nursing and how it affects health care are important to all medical professionals. Topics in under-developed countries such as Ebola and Cholera will have a large impact on the crisis of nursing in the US. Nursing students must be prepared to meet the challenges of global health care by finding solutions for care.

\section{THE SHORTAGE OF NURSES AND ITS GLOBALIMPACT}

Feldstein (2011) [2] defines the nursing shortage as the demand for nurses greater than the number of nurses willing to work for a particular wage. Nursing periodically experiences cyclic shortages that began as early as the 1960s. Government agencies, schools of nursing, and professional nursing agencies have worked together over the years to solve the nursing shortage. The nursing shortage was predicted at $10 \%$ in 2005 and by 2020, could grow to $29 \%$ of the entire nursing population [13].

For new graduates, current predictions might be direr. Health care facilities are able to hire all the experienced nurses they want at current wages in most states. For example, in Nevada, many new graduates are having a difficult time finding jobs due to economic factors, a saturated market, and no-vacancy rates in area hospitals. However, there is hope for the new graduates as the average age for the current working nurse is 47-years. Over 900,000 of the estimated 2.6 million working registered nurses are 50 or over. There has been a recent influx of nurses returning to the workforce due to the poor economy. There is also increased job dissatisfaction associated with nursing in today's health care arena; attributed to increased technologies, increased patient acuities, and increased physical demand [14]. These factors may have contributed to alleviating the current demand for nurses temporarily.

Whether or not there a nursing shortage really exists is a question no one can answer at this point. Some experts like Beall say yes. In her opinion, the recession has relieved the demand for nurses temporarily due to a poor economic situation, but the threat for high vacancy rates still continues in some areas and in the future for most areas. By the year 2025, some 260,000 nurses will be needed to care for the patients in health care facilities in this country [15]. This is especially troubling for several reasons. The Institute of Medicine (IOM) developed several recommendations for nurses in 2010 that could strongly impact the future of nursing [16]. For example, nurses should practice to the full extent of their education and training, achieve higher education, and be full partners with physicians, among others. However, the real shortage lies with nursing faculty [15].

The nursing shortage periodically cycles throughout the American nursing history. Predictions for the 2020 shortage seem to loom large, however, many nurses are middle-aged are working close to retirement. The current relief from the nursing shortage has fooled some educators and officials into thinking the shortage is going away. However, the lull is probably temporary and based on the economy [13]. Educators, professional organizations, and the federal government should act now to grow programs to increase the nursing base. Nursing faculty are experiencing a global shortage as well. The overall number of nursing faculty has steadily decreased within the last decade. Over 75,000 nursing students are turned away from programs due to the lack of appropriate faculty. This is an ongoing global program. The nursing faculty shortage is due to a confluence of factors, including the global migration of nurses, an aging faculty, a reduced younger faculty hiring pool, decreased satisfaction with the faculty role, lack of funding and poor salaries, a seeming persistent devaluation of faculty by academic institutions, increased dependence on contingent faculty, and overall reduction in full time equivalent (FTE) faculty. There seems to be no consensus or plan among nursing professionals to fix this growing problem although more and more literature is being published. Table 1 [17] illustrates global change necessary to find solutions to the nursing shortage. 


\begin{tabular}{lc}
\multicolumn{2}{c}{ Table 1. Global solutions to the nursing shortage } \\
\hline \multicolumn{1}{c}{ Solutions } & Percentage (\%) \\
\hline International cooperative policies and programs & 10.00 \\
Managed migration & 6.67 \\
Educational paradigm change & 28.33 \\
Removal of barriers & 9.17 \\
Centralized data \& strategy & 30.83 \\
Stable funding & 8.33 \\
Nurse scholarship & 3.33 \\
Competitive faculty salary & 3.33 \\
\hline
\end{tabular}

\section{AUTONOMYAS A STATE OF BEING FOR THE EMERGENCY NURSE PRACTITIONER}

Autonomy for the nurse practitioner (NP) is an ongoing practice debate and one that affects quality care, safety, and can determine the course of the development of current and future NP programs in the US. For the emergency NP, autonomy is a pressing issue related to practice because not only do patients present to the emergency room (ER) in emergent conditions, there are many opportunities for NPs in the ER to act autonomously by treating minor injuries, common illnesses, as well as trauma as it presents. Emergency NPs practicing in rural areas may see any number of trauma patients independently and be prepared to treat these patients as well as any treating physician would in the case. Safe practice is an important part of autonomous NP practice as it deals with knowing limitations yet being able to maintain a standard level of care by referring, transferring, or simply sending from fast-track to the main ER. State and federal stakeholders want to see that NPs can maintain a safe, autonomous practice that will not jeopardize the quality of care of the patient or the safety of the patient. Educational programs must gear themselves for the future of nursing and the differences ahead that will embody changes in the way nursing is practiced so that when NPs graduate they will be strong, competent, and ready for autonomous practice.

\subsection{Identification of Practice Issue}

A select group of staff from the University of California at San Francisco (UCSF) (2011) [18] pulled together a project that examined today's autonomous practice of nursing and what would be expected once the next wave of fully insured health care consumers hit the health care arena. Using data from the Robert Wood Johnson Foundation, staff was able to determine that to meet quality guidelines for the next generation of health care consumption, new lines of autonomy must be developed. To meet these needs, educators and students alike must be eager to take on a new view of nursing in this health care society and examine the next step in health care provision. NPs in particular must be prepared to step up and take their place as primary providers for many populations. Rural areas will be in high demand for staffing the NP due to a similar physician shortage [18] and NPs will be expected to act autonomously at rural ERs. Physician collaboration is still required for many states. However, in some states there are guidelines allowing independent NP practice.

\subsection{Background Information}

IOM's recommendation to allow advanced practice nurses practice to the limits of their scope of practice based on their education and training. IOM recommendations include removing restrictions that limit advanced practice nurses from fully using their skills. Some suggestions include expanding Medicare to include NPs as primary providers and increase reimbursement for the services provided just as physicians are reimbursed now. Amend the Medicare program to allow NPs to perform admission assessments and complete admission requirements for patients to enter skilled facilities and home health agencies. These, among other actions, can benefit NPs by providing the much needed autonomy in clinical settings. Rural situations, especially for emergency NPs, will benefit the most from changes in the way reimbursement is presented and NPs practice [16].

According to a survey conducted by Sermo (2011) [19], most physicians believe that independent NP practice will not increase quality health care and will not decrease costs associated with health care spending. Instead, many believe that care quality will be reduced and costs will be increased. Most physicians believe physician-run services will be more efficient and provide better quality of care than that of a NP. For emergency NPs, this is a crucial blow because it is imperative the autonomy that advanced practice nurses seek be approved and data shown that quality not only increases quality of care but cuts costs as well. This will lend authority to the role of the emergency NP as a sole provider and make a step toward changing today's health care environment. 


\subsection{Quality Improvement}

Carolyn Clancy [7] sends a clear message to ER patients about quality. A quality interaction consists of many steps to maintain the safety of the patient. These include verbal read back orders, omitting costly tests that are unnecessary, and cutting wait times. Emergency NPs have a role in this in many ways. In her podcast, Clancy explains that a new frontier of medicine is coming and NPs will be a driving force in seeing that these quality factors are implemented. NPs will use autonomy to see that costly tests are omitted and cut wait times by treating minor injuries quickly without a long wait between triage and seeing a physician. This will also begin to eliminate left without treatment cases (LWOT), a common occurrence in today's ERs. Clancy [7] goes on to talk about the paradigm shift coming from cure to quality care. NPs are in the primary position to provide quality care by spending more time at the bedside, talking to the patient in layman's terms, and providing extensive discharge education. Many consumers are shopping for quality health care. Having a quality initiative in place that addresses the most common causes for complaints in the ER can alleviate many poor hospital patient satisfaction scores. Underscoring NP autonomy in the ER so that NPs can function independently when necessary in the ER can only add to patient satisfaction as NPs function to their full potential, especially in rural settings. In rural settings, quality health care becomes dependent on NPs being allowed to function autonomously as many times the NP is the first contact patients have with the emergency care system.

\subsection{How is Autonomy Measured?}

The American Nurses Association (ANA) strongly advocates autonomy for advanced practice nurses. In Figure 1 [20] provided by ANA, the pinnacle of advanced practice nursing is autonomy.

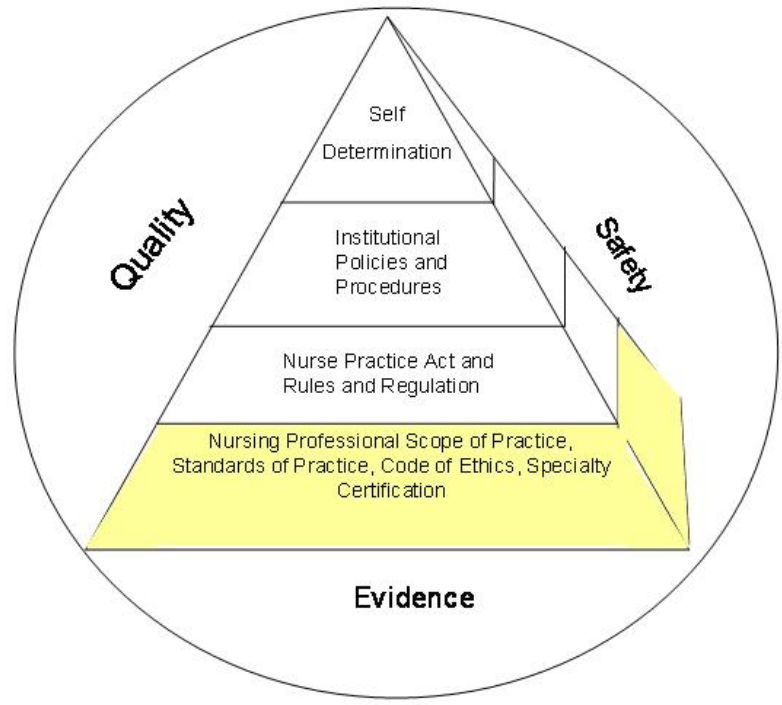

Figure 1. Outcome = Safety, Quality, and Evidence-based Nursing Practice

The goal for advanced practice nurses is to achieve an outcome of "safe, quality, evidence-based nursing" care to the population qualified to practice to For the emergency NP, the outcome desired is remaining in the scope of practice as set forth by the nurse practice act of the state licensing board. Reaching autonomous practice is the goal for providing the three qualities to achieve the outcome of "safe, quality, and evidence-based nursing practice". The quality indicators used are found within the pyramid: "nursing professional scope of practice, standards of practice, code of ethics, and certification of specialty, nurse practice act and rules and regulations, institutional policies and procedures, and self-determination” [20]. The concern for NPs who breach any of these quality indicators is that quality care will decline and patient outcomes will suffer. Also, NP credibility will decrease in the eyes of physicians, other NPs, the federal government, other stakeholders, and patients. The need to maintain quality outcomes is crucial for those who seek autonomous practice as emergency NPs or as NPs in general. Safety issues arise as well when any of these factors are neglected or ignored. Patient safety is also jeopardized when these factors are at ignored and NPs are subject to lose credibility as primary providers when this happens. 


\subsection{Autonomy: A Breach in Costs and Control}

Midlevel providers such as emergency NPs have are showing a greater usage in the ER over the last few years. According to a report by Grinde and Camargo [21], 12.7\% of all ER patients were seen by midlevel providers in 2006. A growing concern by physicians for quality of care has been noted in the article. The concerns listed include the supervision of the midlevel providers. For approximately six million visits, emergency NPs have replaced physicians as primary emergency providers. Concerns, ranging from decreasing staff resources of primary emergency physicians, rising costs of emergency care, financial difficulties of some hospitals, and the reimbursement issues of some insurance companies and the Centers for Medicare and Medicaid (CMS). Overall, emergency physicians in the Grinde and Camargo article [21] seem concerned about the quality of care autonomous NPs are giving their patients based on the education and training programs that are now available. The cost of training a NP is not so far less than training an MD, however, as NPs training require extensive preparation and in depth training beyond the baccalaureate level. Emergency NPs have an opportunity in the coming years to make a difference in the quality data and help cut costs associated with repeat visits and readmissions.

\subsection{Microsystems}

Clinical microsystems are a way to validate clinical systems for patients, families, and other providers. For emergency NPs, the clinical microsystem presented in this paper is the ambulatory community setting where NPs can function autonomously as primary providers. These rural settings serve as primary checkpoints for NPs as they treat patients both emergently and non-urgently. The patient's journey through the rural ER where care is provided by the NP sets up a unique microsystem and concentric view for the health care provider. Patients and families want quality health care and evidence-based care from the provider on duty. For the emergency NP, providing evidence-based care is essential to maintaining a solid practice and good outcomes. Health care systems are in the business to develop more patient relationships and increase patient load [22]. Emergency NPs can contribute to this by using professionalism, practice, and purpose. Retaining caring, competent health care providers is essential in a rural microsystem. Will, execution, ideas, and flow are essential to the survival of a microsystem. In a rural microsystem, the emergency NP can contribute to the by being proactive in legislative actions related to practice, joining and maintaining membership in national organizations, maintaining skill base by attending conferences and workshops, and continuing to promote research and theory in practice. The microsystem is important because it is viewed by the patient and considered important by the patient's decisions. As soon as a patient is in a relationship with the emergency NP, the patient is involved in the microsystem and has a shared stake in the outcomes. The processes that the NP uses to get to the end result, whether it is ordering lab or X-ray, writing a prescription, or simply giving discharge instructions, involves the patient in outcomes. Quality outcomes is the goal of the NP and for quality outcomes to be met, the NP must be aware of all the processes that make up the microsystem. The patient, the setting (rural ER), the processes (writing a prescription, etc.), and the patient all constitute a microsystem [22]. To ensure the patient is satisfied, the NP uses evidence-based nursing.

\subsection{Public Health Management}

Overcrowding of the ER is increasingly becoming a problem for both rural and metropolitan ERs in the US. Understaffing, fewer providers available, and hospital closures are problems that continue to contribute to the overcrowding issues facing ERs today. Emergency NPs can justify the increase in autonomy needed to work as sole providers in rural ERs, work unsupervised in metropolitan ERs to care for minor injuries or illnesses, and serve as first point of contact for the emergency patient. Managers report a high level of satisfaction with the use of emergency NPs in the role as primary providers, fast track providers, and as point of care providers. NPs today exercise a higher level of expertise and autonomy than in the past. Professional development, educational, and training programs are more in depth and require more clinical time and more in depth training than in previous years as well [23]. According to Campo et al., NPs report more confidence in performing procedures and making decisions in autonomous positions. This study is an important landmark study as it finds that NP autonomy is necessary and achievable for practitioners who work in both rural and metropolitan settings. On the job training consisted of some of the NP learning, however, much of the training was learned during clinical experiences. Validating clinical experiences is important when discussing NP autonomy because it is important to achieve a sense of credibility to the educational systems that are producing emergency NPs. Some procedures performed were intubations, insertion of central lines, administration of local anesthetic and stitching a wound, and administration of a nerve block [23]. It is vital to validate the importance of these procedures since they can be the backbone of many emergency procedures. Autonomous practice in a rural setting carries with it a necessity to be 
proficient with skills and procedures. Credibility is essential and validating skills through practice whether on the job or through clinical practice is critical to the autonomy of NPs in the rural setting.

\subsection{Conceptual Framework}

According to Quattrinni and Swan [24], Donabedian's structure-process-outcome conceptual framework provides a useful tool for emergency NPs. The quality of care provided is not only important, but so is the structure of the physical and organizational properties of the settings. The process of care and the return of the patient's health status are a direct outcome of the emergency NP. As a consequence of contact with the NP, the patient can experience either a positive or negative outcome. There are two levels of care in the Donabedian model: interpersonal and technical care. Each outcome reflects the patient's involvement in his or her own care and the provider's ability to provide care for the patient. On a secondary level, the patient's outcomes also include the cost of the health care, length of stay, wait time, and patient satisfaction [24]. The necessity of providing a conceptual framework when working with any concept such as autonomy is to provide a firm basis for the development of practice guidelines and evidentiary support for evidencebased practice.

\section{CASESTUDIES}

\subsection{Case Study One: Cholera}

Haiti is experiencing one of the largest Cholera outbreaks in history as a result of lack of proper sanitation and water supply due to the 2010 earthquake that ripped the country apart. A multitude of organizations including UNICEF, the World Health Organization (WHO), and the United Nations (UN), whose workers are suspected of bringing the disease to Haiti originally, have formed teams of relief and recovery since the epidemic hit the country some months after the quake [25]. The international community has supported Haiti throughout the epidemic and through the support of organizations such as the WHO and UN, funds have helped pay for medical care and vaccinations. Now, support is necessary to prevent Haiti's cholera epidemic from becoming endemic. Even before the earthquake, Haiti's sanitation and water supply was far below other Caribbean country standards; now the time has come to shore up the water supply and negotiate with government officials to improve sanitation standards [25].

Experts called for major donations from contributing countries in 2012 as water and sanitation continue to be a problem in the evolving Cholera outbreak. The Presidents of Haiti and the Dominican Republic joined the Pan American Health Organization/World Health Organization (PAHO/WHO), UNICEF, and the Centers for Disease Control (CDC) in calling for funds to build up the infrastructure of the sanitation and water supply systems in Haiti. Representatives of PAHO/WHO, UNICEF, and the CDC called for donor countries to release funds promised in 2010 for rebuilding [26].

Proper sanitation and a clean water supply will begin to stop the crisis in Haiti. Donor countries are needed to make good their contributions and government officials need to make sure improvements are made. Representatives of world aide agencies are steadily working toward ending the epidemic in Haiti.

\subsection{Case Study Two: Obstetrical Care Limitations in Tanzania}

Adequate obstetrical care is essential to a healthy delivery. Preventing birth defects, infection, and neonatal complications can depend upon adequate and timely prenatal, intranatal, and postnatal care. Economic factors and political issues make health services in third world countries more complicated. Local economies may be lagging and qualified staff may not be available. Global action to improve maternal health over the past few years has included studies to improve outcomes, grants, and allocation of resources. Since 2003, global spending on maternal-child health spending has increased from \$2.1 billion in 2003 to \$3.5 billion in 2006 [27]. Key innovations are necessary to prevent complications due to lack of funding and adequately trained staff. For example, in Tanzania, a lack of adequate resources and a lack of human resources, causes a deficiency in emergency and primary obstetric care [28]. Worldwide aide to suffering countries by agencies such as the Bill and Melinda Gates Foundation has donated funds to shore up a failing system of resource allocation and human resource difficulties. A major deterrent to implementing effecting global policy is finding qualified human resources. Securing quality personnel who are qualified to work in obstetric care is a key component in improving prenatal resources in Tanzania [28]. The purpose of this essay is to examine the current trend of obstetric care in Tanzania and discuss the economic assistance of worldwide grants in improving obstetric care.

Olsen identified the lack of human resources as the main barrier for adequate obstetrical care in Tanzania. Lack of funding, inadequate resources, and a lack of available qualified staff contribute to this situation. Other barriers against adequate obstetrical care include low morale among staff [28]. Limited funding for obstetrical care is also a common problem for finding resources in Tanzania. Of all the problems 
facing Tanzania's obstetrical crisis, finding qualified personnel is of the greatest concern. In Tanzania, 60\% of surgeries are carried out by mid-level practitioners. Most anesthesia, 39.4\%, was provided by nurses, followed closely by physicians at $31.3 \%$. Too often nursing assistants provided anesthesia supervised by a medical officer [29]. In critical times such as during a cesarean section, this could mean the difference between life and death.

There is a poor mix of services among providers in Tanzania with a relatively low access to basic obstetric care and a higher access to comprehensive obstetric care. Most of the deliveries (62\%) were conducted at comprehensive obstetric centers. The majority of complications (60\%) occurred at emergency birthing centers, primarily volunteer facilities [28]. The cost of a simple vaginal delivery in a hospital at a basic obstetric facility is $\$ 6.30$. The cost of a delivery in an emergency clinic is $\$ 12.30$. The cost for surgical delivery is $\$ 69.26$ [30]. Improved planning of resource allocation can only improve services and allow for more a more adequate mix of services. Priorities have to be set by gauging what services are most important. Cost-analysis shows what resources are available and what resources have been spent. This is necessary to analyze the efficiency in which resources have been allocated. About $\$ 0.84$ was spent per individual for maternal services and total costs of pregnancy were about $\$ 20$ per pregnancy [30]. Allocation of resources is essential in this current global economic climate where money is limited.

Safeguarding the children of Tanzania is a priority for some foundations. The Bill and Melinda Gates Foundation in combination with the World Health Organization (WHO) offers a grant to strengthen the

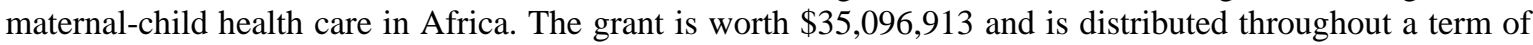
six years and two months [27].

The need for global reform of health policy is evident in the cost of health care and problems facing Tanzania's obstetrical population. Global efforts such as grants like the WHO grant and the efforts by the Bill and Melinda Gates Foundation accentuate the need for future allocations.

\section{CONCLUSION}

Health care reform is necessary in the global market as without reform, diseases such as Ebola, Cholera, and obstetrical problems will continue to exist in third-world countries, ultimately affecting the US as these diseases find their way across international borders. The nursing shortage and nursing faculty shortage should be a primary focus for the IOM and other agencies to develop better methods of training nurses and recruiting nurses for the profession. Autonomy in practice for the emergency NP is a necessity for the advancement of the profession and for the provision of care in both rural and metropolitan settings. Not only do emergency NPs provide a high quality of care, NPs also spend more time with patients and contribute to the primary provider base that is dwindling in numbers. In order for emergency nurse practitioners to meet their full potential, quality care must be provided, but NPs must be given the autonomy to provide care in settings both rural and metropolitan. NPs contribute to the care of both urgent and nonurgent patients, setting standards of care higher than ever with more time spent at bedside, layman's explanations, and extensive discharge teaching. There is no one answer to solving the shortage of providers in the emergency setting. Emergency NPs are trained to handle both emergent and non-urgent cases. Evidence-based practice and a commitment to the profession put emergency NPs in a position to help ease the shortage of the primary care provider in the US emergency room.

\section{ACKNOWLEDGEMENTS}

This work was supported in part by Technology and Healthcare Solutions, Inc. in Mississippi, USA.

\section{REFERENCES}

[1] Galloway S., "Kathleen Mears Memorial Lecture: Personal Accountability: Your Key to Survival in Health Care Reform”,Neurodiagnostic Journal,vol/issue: 54(3), pp. 211-226, 2014.

[2] Feldstein PJ., "Health policy issues: an economic perspective”, Chicago, IL: Health Administration Press, 2011.

[3] The New York Times, "Health care reform: where does it stand now?”,The New York Times, March, 2012. Retrieved http://topics.nytimes.com/top/news/health/diseasesconditionsandhealthtopics/health_insurance_and_managed_care/ health_care_reform/index.html

[4] Pear R., "Many states take a wait-and-see approach on new insurance exchanges”, The New York Times, February 27, 2012. Retrieved from http://www.nytimes.com/2012/02/27/health/policy/a-wait-and-see-approach-for-stateson-insurance-exchanges.html?_r=1\&ref=healthcarereform

[5] Berman ML., "From health care reform to public health reform”,Journal of Law, Medicine \& Ethics, vol/issue: 39(3), pp.328-39, 2011. 
[6] Spetz J.,Kovner CT., "Economics of health care and nursing: Health reform in Massachusetts and the United States: an interview with Jonathan Gruber”,Nursing Economics, vol/issue: 29(5), pp.283-285, 2011.

[7] Clancy C., "The guide to health care quality: How to know it when you see it”,AHRQ Podcast, 2011. Retrieved from http://healthcare411.ahrq.gov/featureAudio.aspx?id=16411health.org.featureAudio/Clancy?id+2

[8] Working Nurse, "Why nursing school grads have trouble finding jobs: a painful shot of reality", 2012. Retrieved from http://www.workingnurse.com/articles/Why-Nursing-School-Grads-Have-Trouble-Finding-Jobs

[9] Terry AJ., Whitman MV., "Impact of the economic Downturn on nursing schools",Nursing Economics, vol/issue: 29(5), pp.252-264, 2011.

[10] Adams LT., "Nursing shortage solutions and America's economic recovery”,Nursing Education Perspectives, vol/issue: 30(6), pp.349, 2009.

[11] Goode L., Krsek,Bednash, “Nurse residency programs: An essential requirement for nursing”,Nursing Economics, vol/issue: 27(3), pp.142-159, 2009.

[12] Coonan PR., "Educational innovation: Nursing's leadership challenge”,Nursing Economics, vol/issue: 26(2), pp. 117-121, 2008.

[13] Ritter D., "The relationship between healthy work environments and retention of nurses in a hospital setting”,Journal of Nursing Management, vol/issue: 19(1), pp.27-32, 2011.

[14] O'Reilly C., "The elephant in the room: employment for new graduate RNs”,Nevada RNformation, vol/issue: 21(1), pp.17, 2012.

[15] Beall F., “Is there really a nursing shortage?”, Georgia Nursing, vol/issue: 71(1), pp.1-2, 2011.

[16] Institute of Medicine, "Future of nursing: campaign for action", 2010. Retrieved from http://www.thefutureofnursing.org/recommendations

[17] Richardson J.,Grose J.,Gill JL.,Sadeghian HB.,Hertel J.,Kelsey J.,"Effect of climate change and resource scarcity on health care”,Nursing Standard, vol/issue: 28(45), pp. 44-49, 2014.

[18] University of California San Francisco, "University of California San Francisco holds discussion on IOM report”, 2011. Retrieved from http://www.thefutureofnursing.org/resource/detail/university-california-san-francisco-holdsdiscussion-iom-nursing-report

[19] Sermo, "Sermo.com's physicians opinions about the impact of allowing NPs to practice independently", 2011. Retrieved from http://www.thefutureofnursing.org/NursingResearchNetwork4

[20] The American Nurses Association (ANA), "Model of professional nurse regulation”, 2006. Retrieved from http://www.nursingworld.org/modelofpracticeregulation

[21] Grinde AA., Camargo CA., “Trends in midlevel provider utilization. Academic Emergency Medicine”,Official Journal of the Society for Academic Emergency Medicine, vol/issue: 17(3), pp.344, 2011.

[22] Nelson E., Godfrey M., Batalden P., et al., "Clinical microsystems part 1: the building blocks of health systems”,Joint Commission Journal on Quality and Patient Safety, vol/issue: 34(7), pp.367-378, 2008.

[23] YCampo T., McNulty R., Sabitini M., Fitzpatrick J., "Nurse practitioner performing procedures with confidence and independence in the emergency care setting”,Advanced Emergency Nursing Journal, vol/issue: 30(2), pp.153170, 2008.

[24] Quattrinni V., Swan B., “Evaluating care in ED fast tracks”,Journal of Emergency Nursing, vol/issue: 37(1), pp.4046, 2011.

[25] Disasters: Preparedness \& Mitigation in the Americas, "Haiti: moving from emergency to a fragile recovery”,Disasters: Preparedness \& Mitigation in the Americas, no. 115, pp.7, 2011.

[26] Singh P., "Experts call for major investments in water and sanitation to end Cholera in Haiti and the Dominican”,Journal of the American Society of Tropical Medicine and Hygiene, vol/issue: 117(3), pp.1251-1266, 2012.

[27] Bill and Melinda Gates Foundation, “Strategy overview: Maternal, child, and neonatal health”, 2012. Retrieved from http://www.gatesfoundation.org/maternalnewbornandchildhealth/Pages/default.aspx

[28] Olsen ØE., "The impact of global health initiatives on trust in health care provision under extreme resource scarcity: presenting an agenda for debate from a case study of emergency obstetric care in Northern Tanzania”,Health Research Policy \& Systems, no. 8, pp.14-24, 2010.

[29] Kruk ME., Wladis A., Mbembati N., Ndao-Brumblay SK., et al., "Human resource and funding constraints for essential surgery in district hospitals in Africa: a retrospective cross-sectional survey”,PLoS Medicine, vol/issue: 7(3), pp.1-11, 2010.

[30] von Both C., Jahn A., Flessa S., "Costing maternal health services in South Tanzania: A case study from Mtwara urban district”,European Journal of Health Economics, vol/issue: 9(2), pp.103-115, 2008. 


\section{BIOGRAPHIES OF AUTHORS}

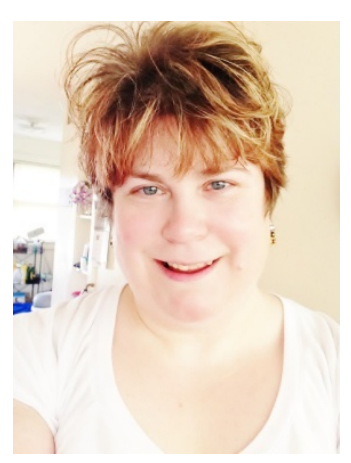

Ms. Cheryl Ann Alexander is a graduate of the University of Phoenix where she earned a dual Master's degree in Healthcare Administration and Nursing, and she is currently a doctoral candidate and will graduate soon. She is Chairman of the Board of Technology\& Healthcare Solutions, Inc., a nonprofit research and consultant firm located in Greenwood, MS, US, which promotes technology solutions as methods to reduce costs and errors in healthcare management and improve quality care. She has extensive clinical knowledge in a wide variety of clinical backgrounds, and a firm grasp of engineering and technology concepts through continuing education and workshops. She is a member of both engineering and healthcare organizations, and is working as managing editor for a leading journal in engineering.

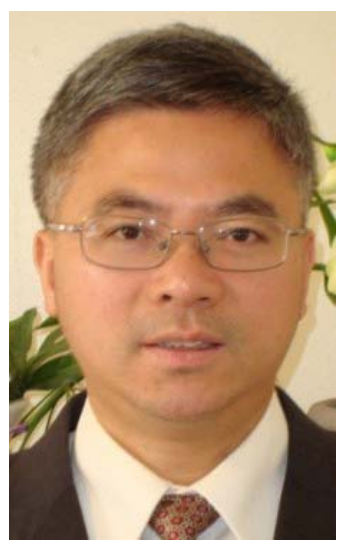

Dr. Lidong Wang is an Associate Professor in the Department of Engineering Technology at Mississippi Valley State University, USA. He had conducted research at the University of South Carolina, Ohio State University, and Mississippi State University; and conducted projects supported by the Department of Defense (DOD), the National Science Foundation (NSF), and the National Aeronautics and Space Administration (NASA) before he moved to Mississippi Valley State University in 2007. His current research interests include: big data, biometrics, and radio frequency identification (RFID) in medical applications and health care. He has published 55 papers in various journals.Dr. Wang has been invited to review papers by over 10 professional journals. He has also been invited by four professional journals to act as their guest editor. He has been the Editor-in-Chief of the International Journal of Automated Identification Technology (IJAIT) for six years. 